\title{
Lattice-matched Cu2ZnSnS4/CeO2 solar cell with open circuit voltage boost
}

Crovetto, Andrea; Yan, Chang; landolo, Beniamino; Zhou, Fangzhou; Stride, John; Schou, Jørgen; Hao, Xiaojing; Hansen, Ole

Published in:

Applied Physics Letters

Link to article, DOI:

$10.1063 / 1.4971779$

Publication date:

2016

Document Version

Publisher's PDF, also known as Version of record

Link back to DTU Orbit

Citation (APA):

Crovetto, A., Yan, C., landolo, B., Zhou, F., Stride, J., Schou, J., Hao, X., \& Hansen, O. (2016). Lattice-matched $\mathrm{Cu}_{2} \mathrm{ZnSnS} / \mathrm{CeO}$, solar cell with open circuit voltage boost. Applied Physics Letters, 109, [233904]. https://doi.ofg/10.4063/1.4971779

\section{General rights}

Copyright and moral rights for the publications made accessible in the public portal are retained by the authors and/or other copyright owners and it is a condition of accessing publications that users recognise and abide by the legal requirements associated with these rights.

- Users may download and print one copy of any publication from the public portal for the purpose of private study or research.

- You may not further distribute the material or use it for any profit-making activity or commercial gain

- You may freely distribute the URL identifying the publication in the public portal 


\section{AIP Applied Physics Letters}

\section{Lattice-matched Cu2ZnSnS4/CeO2 solar cell with open circuit voltage boost}

Andrea Crovetto, Chang Yan, Beniamino landolo, Fangzhou Zhou, John Stride, Jørgen Schou, Xiaojing Hao, and Ole Hansen

Citation: Applied Physics Letters 109, 233904 (2016); doi: 10.1063/1.4971779

View online: http://dx.doi.org/10.1063/1.4971779

View Table of Contents: http://scitation.aip.org/content/aip/journal/apl/109/23?ver=pdfcov

Published by the AIP Publishing

\section{Articles you may be interested in}

Band slope in CdS layer of $\mathrm{ZnO}: \mathrm{Ga} / \mathrm{CdS} / \mathrm{Cu} 2 \mathrm{ZnSnS} 4$ photovoltaic cells revealed by hard X-ray photoelectron spectroscopy

Appl. Phys. Lett. 109, 203902 (2016); 10.1063/1.4967979

Band offset at the heterojunction interfaces of CdS/ZnSnP2, ZnS/ZnSnP2, and In2S3/ZnSnP2

J. Appl. Phys. 119, 193107 (2016); 10.1063/1.4950882

In situ process monitoring during multistage coevaporation of Cu2ZnSnS4 thin films

J. Vac. Sci. Technol. A 33, 021206 (2015); 10.1116/1.4906787

Towards a CdS/Cu2ZnSnS4 solar cell efficiency improvement: A theoretical approach

Appl. Phys. Lett. 105, 233501 (2014); 10.1063/1.4903826

Effects of potassium doping on solution processed kesterite Cu2ZnSnS4 thin film solar cells

Appl. Phys. Lett. 105, 223903 (2014); 10.1063/1.4903500

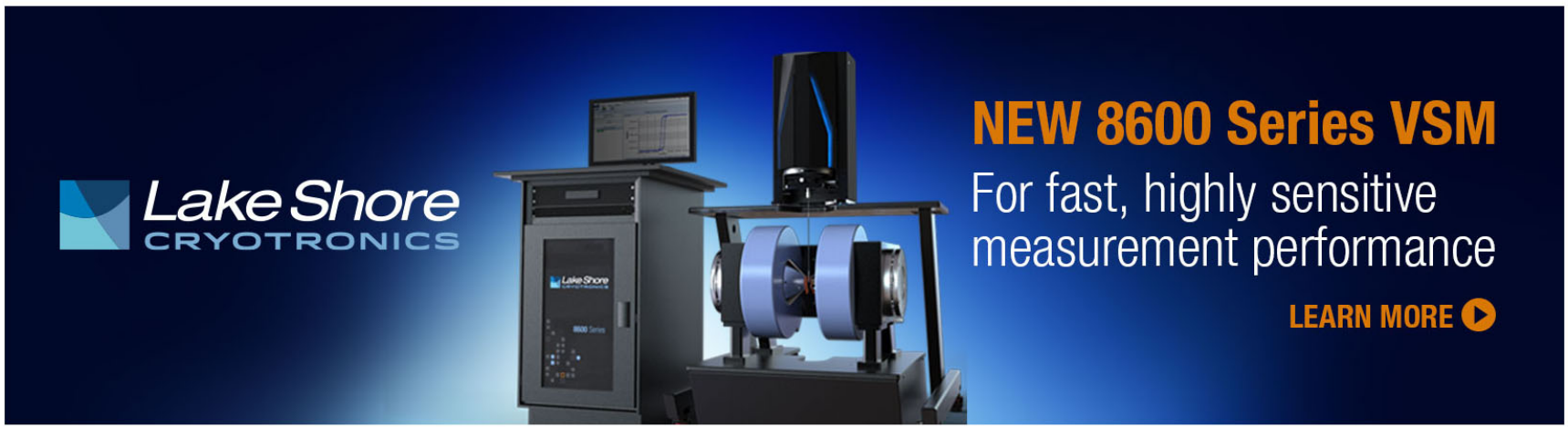




\title{
Lattice-matched $\mathrm{Cu}_{2} \mathrm{ZnSnS} / \mathrm{CeO}_{2}$ solar cell with open circuit voltage boost
}

\author{
Andrea Crovetto, ${ }^{1,2, a)}$ Chang Yan, ${ }^{2}$ Beniamino landolo, ${ }^{3}$ Fangzhou Zhou, ${ }^{2}$ John Stride, ${ }^{4}$ \\ Jørgen Schou, ${ }^{5}$ Xiaojing Hao, ${ }^{2, b)}$ and Ole Hansen ${ }^{1,6}$ \\ ${ }_{1}^{1}$ DTU Nanotech, Technical University of Denmark, DK-2800 Kongens Lyngby, Denmark \\ ${ }^{2}$ School of Photovoltaic and Renewable Energy Engineering, University of New South Wales, Sydney, \\ NSW 2052, Australia \\ ${ }^{3}$ DTU CEN, Center for Electron Nanoscopy, DK-2800 Kongens Lyngby, Denmark \\ ${ }^{4}$ School of Chemistry, University of New South Wales, Sydney, NSW 2052, Australia \\ ${ }^{5}$ DTU Fotonik, Technical University of Denmark, DK-4000 Roskilde, Denmark \\ ${ }^{6} V$-SUSTAIN, Villum Center for the Science of Sustainable Fuels and Chemicals, Technical University \\ of Denmark, DK-2800 Kongens Lyngby, Denmark
}

(Received 3 October 2016; accepted 23 November 2016; published online 6 December 2016)

We report a reproducible enhancement of the open circuit voltage in $\mathrm{Cu}_{2} \mathrm{ZnSnS}_{4}$ solar cells by introduction of a very thin $\mathrm{CeO}_{2}$ interlayer between the $\mathrm{Cu}_{2} \mathrm{ZnSnS}_{4}$ absorber and the conventional $\mathrm{CdS}$ buffer. $\mathrm{CeO}_{2}$, a non-toxic earth-abundant compound, has a nearly optimal band alignment with $\mathrm{Cu}_{2} \mathrm{ZnSnS}_{4}$ and the two materials are lattice-matched within $0.4 \%$. This makes it possible to achieve an epitaxial interface when growing $\mathrm{CeO}_{2}$ by chemical bath deposition at temperatures as low as $50^{\circ} \mathrm{C}$. The open circuit voltage improvement is then attributed to a decrease in the interface recombination rate through formation of a high-quality heterointerface. Published by AIP Publishing. [http://dx.doi.org/10.1063/1.4971779]

$\mathrm{Cu}_{2} \mathrm{ZnSn}(\mathrm{S}, \mathrm{Se})_{4}$ compounds are among the materials that are currently considered as potentially suitable for terawatt-scale solar energy production. The pure-sulfide material $\mathrm{Cu}_{2} \mathrm{ZnSnS}_{4}$ (CZTS) is particularly interesting because it avoids the relatively scarce element $\mathrm{Se}$, and it has a larger band gap $(1.5 \mathrm{eV})$, which is appropriate both for a single-junction solar cell and for a top absorber in a tandem solar cell architecture. ${ }^{1}$ Even though its highest reported power conversion efficiency so far $(9.1 \%)$ was achieved with a CdS heterointerface partner, or buffer layer, ${ }^{2}$ interface recombination is still the dominant voltage loss mechanism in the solar cell, ${ }^{3}$ which suggests that CdS is not the ideal partner of CZTS. Despite promising results achieved with $(\mathrm{Zn}, \mathrm{Cd}) \mathrm{S}$ and $(\mathrm{Zn}, \mathrm{Sn}) \mathrm{O}$ buffer layers, ${ }^{4,5}$ no alternative materials to date have outperformed the highest efficiency ${ }^{2}$ or the highest open circuit voltage ${ }^{6}$ achieved with a CdS heterojunction partner.

The open circuit voltage $V_{\text {oc }}$ of a solar cell limited by interface recombination can be expressed as

$$
V_{\mathrm{oc}}=\frac{E_{\mathrm{i}}}{q}-\frac{k T}{q} \ln \left(\frac{q S_{\mathrm{p}} N_{\mathrm{v}}}{J_{\mathrm{sc}}}\right)
$$

for a p-type absorber with an inverted heterointerface, i.e., with holes as minority carriers at the interface. ${ }^{7} E_{\mathrm{i}}$ is the interface band gap, $q$ is the elementary charge, $k$ is the Boltzmann's constant, $T$ is the temperature, $N_{\mathrm{v}}$ is the effective density of states in the valence band, $J_{\text {sc }}$ is the short circuit current, and $S_{\mathrm{p}}$ is the interface recombination velocity of holes. By modeling interface recombination as ShockleyRead-Hall recombination through a single interface defect level, $S_{\mathrm{p}}$ can be expressed as

\footnotetext{
${ }^{\text {a)} E l e c t r o n i c ~ m a i l: ~ a n c r o @ n a n o t e c h . d t u . d k ~}$

b)Electronic mail: xj.hao@unsw.edu.au
}

$$
S_{\mathrm{p}}=N_{\mathrm{i}} \sigma_{\mathrm{p}} v_{\mathrm{th}},
$$

where $N_{\mathrm{i}}$ is the area density of interface defects, $\sigma_{\mathrm{p}}$ is a cross section describing how efficiently the holes are captured by the defect, and $v_{\text {th }}$ is the thermal velocity. ${ }^{8}$

Eqs. (1) and (2) show that decreasing the interface defect density $N_{\mathrm{i}}$ can be a way to improve the open circuit voltage in a solar cell limited by interface recombination. By analogy to high-efficiency solar cell technology based on III-V semiconductors, ${ }^{9}$ this can be achieved by ensuring epitaxial growth of the buffer material on the absorber material. In the absence of epitaxial growth, a large density of atomic dislocations will exist at the interface, which leads to formation of allowed electronic states within the interface bandgap, thus increasing $N_{\mathrm{i}}$ and enhancing interfacial Shockley-Read-Hall recombination. Epitaxial growth is facilitated by a small lattice mismatch between the two heterojunction materials. ${ }^{9}$ While CdS has a reasonably small lattice mismatch with the absorber materials $\mathrm{Cu}(\mathrm{In}, \mathrm{Ga}) \mathrm{Se}_{2}(\sim 1.5 \%)$ and $\mathrm{Cu}_{2} \mathrm{ZnSnSe}_{4}$ $(\sim 2.4 \%)$, its mismatch with CZTS is much larger ( 7\%). A high value of $N_{\mathrm{i}}$ can therefore be anticipated at the CZTS/ CdS interface.

To address this problem, we carried out an initial investigation of the non-toxic, earth abundant material ${ }^{10} \mathrm{CeO}_{2}$ as a heterojunction partner of CZTS. $\mathrm{CeO}_{2}$ has a nearly perfect lattice match ${ }^{11}$ with CZTS (lattice constant of CZTS: $5.43 \AA$; lattice constant of $\mathrm{CeO}_{2}: 5.41 \AA$; thus a lattice mismatch under $0.4 \%$ ). This opens the possibility for a high-quality epitaxial interface, which may alleviate the interface recombination problem. $\mathrm{CeO}_{2}$ also has a wide indirect bandgap ${ }^{12,13}$ of $3.3 \mathrm{eV}$, which minimizes parasitic light absorption. We note that, based on Eq. (1), the lattice mismatch at the $\mathrm{CeO}_{2} / \mathrm{CdS}$ interface is not expected to limit $V_{\text {oc }}$, since $E_{\mathrm{i}}$ is much larger at the $\mathrm{CeO}_{2} / \mathrm{CdS}$ interface than at the $\mathrm{CZTS} / \mathrm{CeO}_{2}$ interface.

CZTS films were prepared by co-sputtering $\mathrm{Cu} / \mathrm{ZnS} / \mathrm{SnS}$ precursors on Mo-coated soda lime glass using a magnetron 
sputtering system (AJA International, Inc., model ATC-2200) as presented in detail before. ${ }^{14}$ Two types of elemental compositions were targeted in different CZTS precursors within the same batch: the first $(\mathrm{C} 1)$ with $\mathrm{Cu} / \mathrm{Sn}=1.9$ and $\mathrm{Zn} / \mathrm{Sn}$ $=1.25$; the second $(\mathrm{C} 2)$ with $\mathrm{Cu} / \mathrm{Sn}=1.8$ and $\mathrm{Zn} / \mathrm{Sn}=1.25$. $\mathrm{C} 1$ and $\mathrm{C} 2$ were chosen because the final solar cell efficiency is very sensitive to the sample stoichiometry, especially to the $\mathrm{Cu} / \mathrm{Sn}$ ratio. ${ }^{15}$ These precursors were then annealed using Rapid Thermal Processor (AS-One 100) in a S- and Sn-containing atmosphere at $560^{\circ} \mathrm{C}$. The $\mathrm{S}$ atmosphere compensates for $\mathrm{S}$ substoichiometry in the precursors and the addition of Sn stabilizes CZTS against decomposition reactions. ${ }^{16}$ $\mathrm{CeO}_{2}$ films were deposited on CZTS by chemical bath deposition (CBD) at $50^{\circ} \mathrm{C}$ in a weakly acidic solution (pH:6) containing $10 \mathrm{mM} \mathrm{Ce}\left(\mathrm{CH}_{3} \mathrm{COO}\right)_{3}$ and $5 \mathrm{mM} \mathrm{KClO}_{3}$ in Milli-Q water under mild stirring. The expected chemical reactions resulting in thin film deposition are those presented in previous work. ${ }^{17} \mathrm{CdS}(60 \mathrm{~nm})$ was deposited by CBD with a previously described process. ${ }^{14} \mathrm{ZnO}(60 \mathrm{~nm})$ and indium tin oxide (ITO, $200 \mathrm{~nm}$ ) layers were deposited by RF magnetron sputtering, followed by an Al contact grid. No antireflection coating was applied. The total area of the final cells $\left(0.23 \mathrm{~cm}^{2}\right)$ was defined by mechanical scribing. Three different solar cell architectures were fabricated in this work as shown in Fig. 1. In the first architecture (A1), CdS is completely replaced by a stand-alone $30 \mathrm{~nm} \mathrm{CeO}_{2}$ buffer layer deposited with a $100 \mathrm{~min}$ process. In the second architecture (A2), a thin $\mathrm{CeO}_{2}$ layer of estimated thickness between 1 and $5 \mathrm{~nm}$ is inserted between CZTS and the standard CdS buffer layer using a $10-20 \mathrm{~min}$ deposition process. The reference architecture (Fig. 1) is a conventional CZTS solar cell structure without $\mathrm{CeO}_{2}$. Only very weak n-type conductivity ${ }^{18}$ has been reported for $\mathrm{CeO}_{2}$ and, in fact, the resistivity of the films synthesized in this work was too high to be measured with conventional four-point probe apparatus. Therefore, the $\mathrm{CeO}_{2}$ layer in the solar cell can be regarded as completely depleted. In the case of architecture $\mathrm{A} 2$, the $\mathrm{CeO}_{2}$ layer is so thin that it is not expected to modify significantly the original electric field profile of the reference architecture.

Scanning electron microscope images were taken with a FEI-Nova NanoSEM 450 instrument at $2 \mathrm{kV}$ beam voltage. High-resolution bright-field transmission electron microscope images (HRTEM) were taken with a FEI-Titan 80-300 TEM, at $300 \mathrm{kV}$ beam voltage. X-ray photoelectron spectroscopy (XPS) was performed with a Thermo Scientific

reference
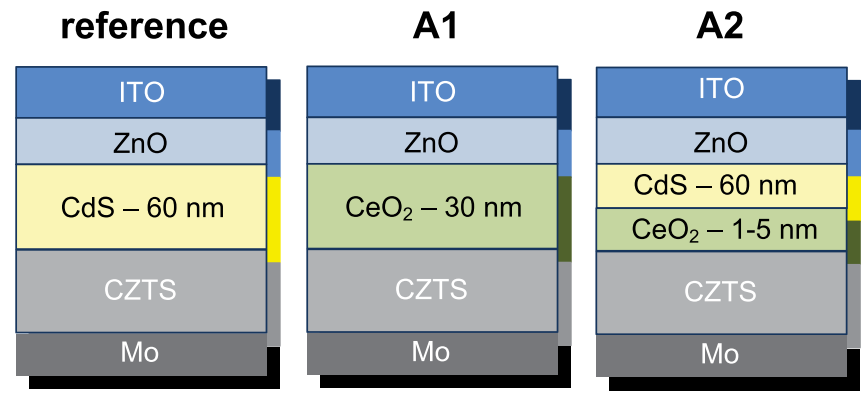

FIG. 1. Schematic drawing of the A1 architecture with a $30 \mathrm{~nm}$ stand-alone $\mathrm{CeO}_{2}$ buffer layer and the A2 architecture with a $1-5 \mathrm{~nm} \mathrm{CeO}_{2}$ interlayer between CZTS and CdS. The reference architecture is a standard CZTS solar cell structure.
K-Alpha instrument with a monochromatized $\mathrm{Al} \mathrm{K}_{\alpha} \mathrm{X}$-ray source. The binding energy scale was calibrated using the adventitious $\mathrm{C} 1 \mathrm{~s}$ peak at $284.8 \mathrm{eV}$. An electron flood source was employed to limit the charging effects in $\mathrm{CeO}_{2} \cdot{ }^{19} \mathrm{CeO}_{2}$ was found by others to be reduced to $\mathrm{Ce}_{2} \mathrm{O}_{3}$ both under prolonged X-ray exposure ${ }^{20}$ and under ion beam sputtering. ${ }^{19}$ Indeed, by inspection of the $\mathrm{Ce} 3 \mathrm{~d}$ spectrum and of the valence band edge, reduction effects were evident in our films even at the lowest ion beam energy $(200 \mathrm{eV})$ available in the XPS setup. Therefore, no sputter cleaning was performed on our samples. XPS data analysis was performed with the Avantage 5.948 software (Thermo Scientific). Current-voltage (JV) characteristics on finished devices were measured under AM 1.5G illumination with a solar simulator from PV Measurement and a Keithley 2400 source meter calibrated with a standard Si reference.

Before discussing the solar cell results, we want to answer some basic questions about the quality of deposited $\mathrm{CeO}_{2}$ films. The first question is adhesion. By depositing $\mathrm{CeO}_{2}$ on glass/Mo substrates, it was found that the films deposited from a solution with a $\mathrm{KClO}_{3}$ concentration of $10 \mathrm{mM}$ or above were easily peeled off by scotch tape. However, already at a $\mathrm{KClO}_{3}$ concentration of $5 \mathrm{mM}$, the films were strongly adherent with no peel-off by repeated scotch tape application. A $\mathrm{KClO}_{3}$ concentration of $5 \mathrm{mM}$ was therefore chosen for the deposition process. The maximum $\mathrm{CeO}_{2}$ thickness on CZTS that could be achieved in a single chemical bath deposition run was about $30 \mathrm{~nm}$ with a $100 \mathrm{~min}$ process (Fig. S1(a), supplementary material).

The second question is whether the deposited film indeed consists of the desired $\mathrm{CeO}_{2}$ material. The fast Fourier transform (FFT) of cross-sectional TEM images of the deposited film yields a pattern that is compatible with $\mathrm{CeO}_{2}$ and not with the main competing phase $\mathrm{Ce}_{2} \mathrm{O}_{3}$ (Fig. 2(c)). However, the TEM analysis involves very small regions (few nm). Raman spectroscopy was then performed over a much larger analysis area (about $2 \mu \mathrm{m}$ diameter). Only one additional Raman peak at $461 \mathrm{~cm}^{-1}$ was revealed on CZTS/ $/ \mathrm{CeO}_{2}$ bilayers compared to a bare CZTS spectrum (Fig. S2, supplementary material). The peak corresponds to the first-order-allowed Raman mode of $\mathrm{CeO}_{2}$, with a small red shift due to size effects. ${ }^{21}$ Finally, XPS characterization was performed over an even larger analysis area (about $400 \mu \mathrm{m}$ diameter). All the XPS peaks corresponding to Ce $3 \mathrm{~d}$ core levels were fitted and attributed to either $\mathrm{CeO}_{2}$ or $\mathrm{Ce}_{2} \mathrm{O}_{3}$ according to reference spectra ${ }^{22}$ (Fig. S3, supplementary material). The fraction of $\mathrm{CeO}_{2}$ present in the deposited film is estimated as $70.4 \%$ with this method. Hence, some $\mathrm{Ce}_{2} \mathrm{O}_{3}$ inclusion should be expected. Since $\mathrm{Ce}_{2} \mathrm{O}_{3}$ is not lattice-matched to CZTS, and it has a band gap ${ }^{13}$ almost $1 \mathrm{eV}$ lower than that of $\mathrm{CeO}_{2}$, we assume that $\mathrm{Ce}_{2} \mathrm{O}_{3}$ inclusions promote interface recombination and reduce the open circuit voltage enhancement that could be achieved with a pure $\mathrm{CeO}_{2}$ layer.

The third question is whether the deposited film provides a complete coverage of the underlying CZTS layer. SEM images of a $30 \mathrm{~nm}$-thick $\mathrm{CeO}_{2}$ film (Fig. 3) show some non-uniform coverage in correspondence of CZTS grain boundaries and some smaller isolated dips in the $\mathrm{CeO}_{2}$ film profile, which may be interpreted as pinholes. The area 


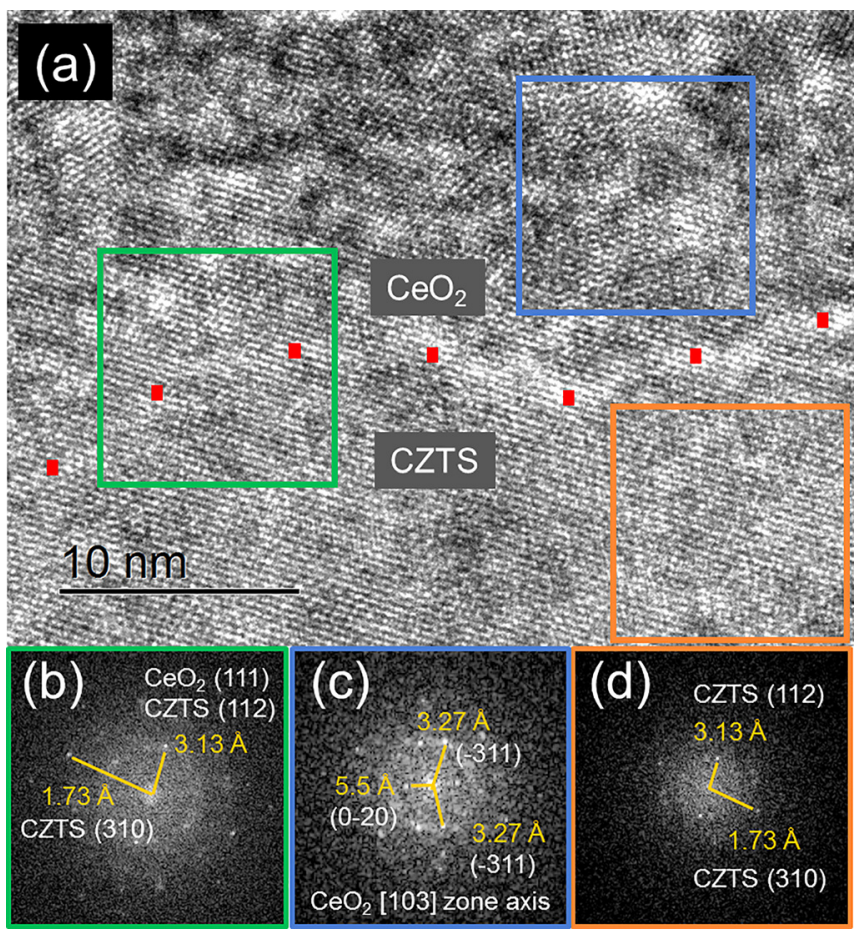

FIG. 2. (a) Cross-sectional HRTEM image across the interface between $\mathrm{CeO}_{2}$ (top) and CZTS (bottom). (b) FFT of a selected region across the interface. A reflection at $3.13 \AA$ is visible, corresponding to the distance between (111) planes of $\mathrm{CeO}_{2}$ and between the (112) planes of CZTS. (c) FFT of a selected region within $\mathrm{CeO}_{2}$. The diffractogram can be indexed as a $\mathrm{CeO}_{2}$ crystal along with [103] as the zone axis. (d) FFT of a selected region within CZTS. Reflections corresponding to the (112) and (310) planes are visible.

fraction of CZTS that is covered by $\mathrm{CeO}_{2}$ can be estimated by comparing the peak intensity of $\mathrm{Ce}, \mathrm{Cu}, \mathrm{Zn}$, and $\mathrm{Sn}$ core levels by XPS, as explained in the supplementary material. The covered area is then estimated as $62 \%, 94 \%$, and $95 \%$ for the films deposited for 20,60, and $90 \mathrm{~min}$, with estimated thicknesses of $1-5,15$, and $25 \mathrm{~nm}$, respectively. Thus, it seems as if the very thin films ( $20 \mathrm{~min}$ deposition time) employed in architecture A2 may have rather poor coverage. However, in that case the $\mathrm{CeO}_{2}$ thickness is comparable to the XPS probing depth (about $2 \mathrm{~nm}$ ). Therefore, part of the CZTS signal is likely to originate from CZTS buried under $\mathrm{CeO}_{2}$ so that the covered fraction is in reality higher. The consequence of incomplete coverage is simply the coexistence of $\mathrm{CZTS} / \mathrm{CeO}_{2}$ and $\mathrm{CZTS} / \mathrm{CdS}$ heterojunctions in parallel to the solar cells.

The fourth question is whether $\mathrm{CeO}_{2}$ forms an epitaxial interface with CZTS, as may be expected by their excellent

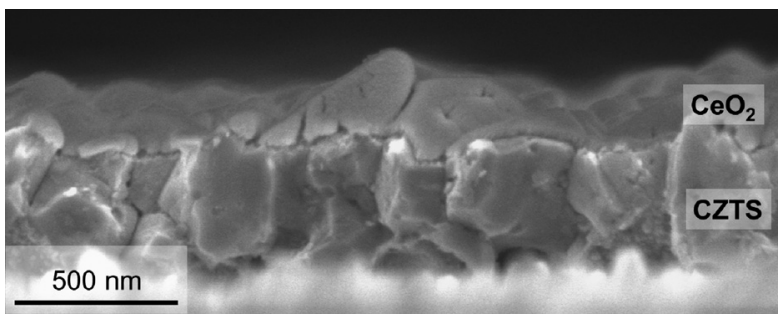

FIG. 3. The cross sectional SEM image of a $\mathrm{CeO}_{2}$ film grown on CZTS used for architecture A1. The film is about $30 \mathrm{~nm}$ thick, which is the maximum thickness that could be achieved with a single CBD process in this work. Some scattered pinholes and inhomogeneous coverage of the grain boundaries are seen. lattice match. The HRTEM image in Fig. 2(a) shows that the atomic arrangement on the CZTS side continues on the $\mathrm{CeO}_{2}$ side for a few $\mathrm{nm}$, thus demonstrating that an epitaxial interface can be achieved despite the low deposition temperature. Analysis of the FFT pattern across the interface (Fig. 2(b)) reveals that epitaxy occurs along the CZTS(112)$\mathrm{CeO}_{2}$ (111) direction, similar to what was recently observed on a CZTS/CdS interface. ${ }^{23} \mathrm{~A}$ few $\mathrm{nm}$ away from the interface, $\mathrm{CeO}_{2}$ is nanocrystalline with an average grain size less than $5 \mathrm{~nm}$, as inferred from TEM images (Fig. 2(a)) and by quantitative analysis of Raman peak broadening (Fig. S2, supplementary material). We emphasize, however, that epitaxial growth was not observed at most interface locations imaged by TEM in this work, as shown for example, in Fig. S1(b), supplementary material.

The fifth and final question is the band alignment of $\mathrm{CeO}_{2}$ with CZTS. It is well known that a moderate spike-like conduction band offset $(\mathrm{CBO})$ at the heterointerface, in the $0-0.4 \mathrm{eV}$ range, is optimal as it reduces interface recombination without blocking photocurrent transport. ${ }^{24}$ The valence band offset (VBO) was estimated by XPS as shown in Fig. 4. The experimental (bulk) band gaps of the two materials were then added to the $\mathrm{VBO}$ to finally obtain a $\mathrm{CBO}$ of $-0.12 \pm 0.20 \mathrm{eV}$. For the $\mathrm{CeO}_{2}$ indirect gap, we used a value of $3.3 \pm 0.1 \mathrm{eV}$ measured by the internal photoemission yield. ${ }^{12}$ The extracted CBO is only slightly below the optimal range, and it is actually more favorable than the previously measured CZTS/CdS band offset. ${ }^{25}$ Considering the many possible sources of error in the measurement, including the use of as-deposited surfaces for analysis, this is considered as a promising result. We also note that the $\mathrm{CeO}_{2}$ Fermi level lies about $2.7 \mathrm{eV}$ above the valence band, which indicates that $\mathrm{CeO}_{2}$ is n-type in the analysis region, similar to previous reports. ${ }^{22,26}$

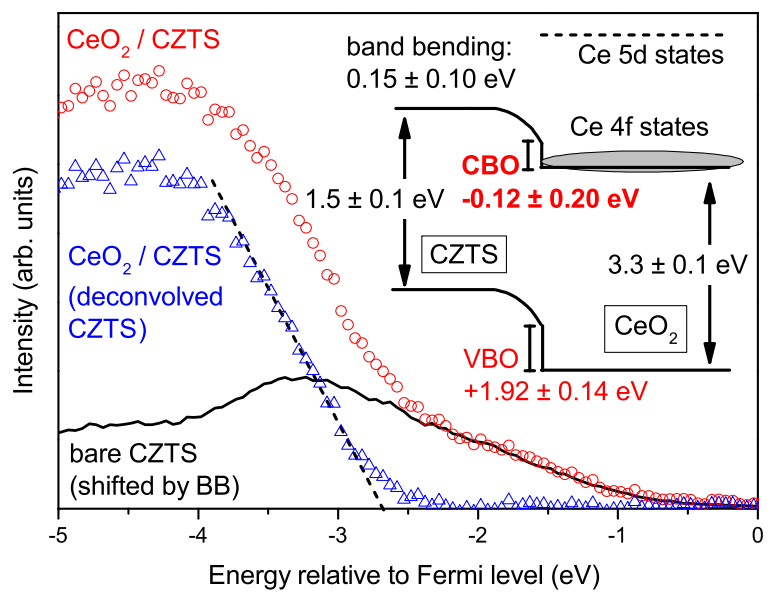

FIG. 4. $\mathrm{CZTS} / \mathrm{CeO}_{2}$ band alignment extracted by XPS. The valence band maximum (VBM) of CZTS with respect to the Fermi level is $-0.60 \pm 0.10 \mathrm{eV}$ in a bare CZTS sample and $-0.75 \pm 0.10 \mathrm{eV}$ in a CZTS sample coated with a thin $\mathrm{CeO}_{2}$ layer ( 20 min deposition time, red circles). From this, band bending (BB) in CZTS is estimated as $0.15 \pm 0.10 \mathrm{eV}$. This is also confirmed from the average shift in the $\mathrm{Cu} 2 \mathrm{p}, \mathrm{Zn} 2 \mathrm{p}$, and $\mathrm{Sn} 3 \mathrm{~d}$ core levels between the bare CZTS sample and the $\mathrm{CeO}_{2} / \mathrm{CZTS}$ sample. Shifting the XPS spectrum of the bare CZTS sample by the BB (black line) allows deconvolution of the $\mathrm{CeO}_{2}$ valence band signal (blue triangles), located $-2.67 \pm 0.10 \mathrm{eV}$ below the Fermi level. The shifted spectrum of bare CZTS (black line) fits well with the $\mathrm{CeO}_{2} / \mathrm{CZTS}$ spectrum until the onset of the $\mathrm{CeO}_{2}$ valence band, as expected. 


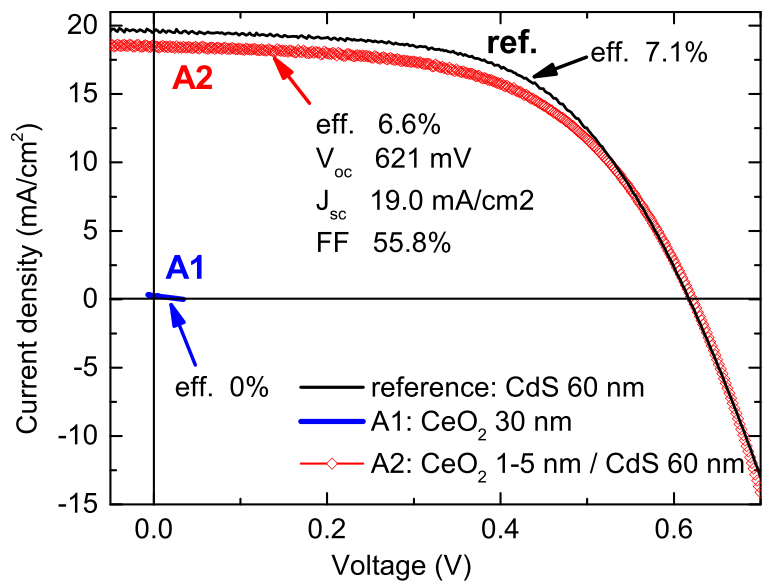

FIG. 5. Illuminated current-voltage characteristics of the best solar cells with the A1 and A2 architectures, together with the best solar cell with the reference architecture.

The current-voltage characteristics of the three best solar cells fabricated with the three different architectures are shown in Fig. 5. A small improvement in open circuit voltage is achieved by architecture A2 with respect to the reference architecture. The accompanying degradation in short circuit current will be discussed in the following. Interestingly, the statistics shown in Fig. 6 indicate that the $V_{\text {oc }}$ boost is reproducible over two separate batches (i) and (ii) regardless of precursor composition ( $\mathrm{C} 1$ or $\mathrm{C} 2)$. In all those cases, the open circuit voltage of the solar cells with A2 architecture is always between $20 \mathrm{mV}$ and $100 \mathrm{mV}$ higher than in the corresponding solar cells with the standard CdS architecture. Additional statistics in Fig. S6 (supplementary material) confirm this trend. The highest open circuit voltage achieved in this study with the A2 architecture was $641 \mathrm{mV}$, and the highest efficiency was $6.6 \%$ (Fig. 5). Conversely, complete current blocking and no photovoltaic effect was observed in the solar cells with a stand-alone $\mathrm{CeO}_{2}$ buffer layer (architecture A1 in Fig. 5).

To interpret these results, we refer to the band structure of $\mathrm{CeO}_{2}{ }^{13}$ What has been referred to as the "conduction band" in this work is a band consisting of highly localized $\mathrm{Ce}$ 4f states, $3.3 \mathrm{eV}$ above the valence band as mentioned before. ${ }^{12}$ However, localization of states in this band implies



(a)

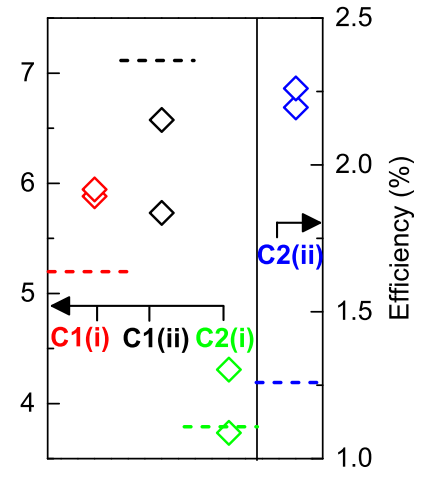

(b)
FIG. 6. Comparison of open circuit voltage (a) and conversion efficiency (b) between solar cells with the A2 architecture (diamond data points) and a reference solar cell with a pure CdS buffer layer (dashed line) within the same batch. C1 and C2 are two different CZTS compositions; (i) and (ii) are two different batches. Each data point represents the highest-efficiency solar cell within a chip containing 12 devices. that the electron effective mass is very high, and hence the electron mobility is very low. This can be inferred by a nearly complete lack of dispersion of those states in reciprocal space. ${ }^{13}$ For this reason, a band consisting mostly of Ce $5 \mathrm{~d}$ states, which lies about $6 \mathrm{eV}$ above the valence band has lighter effective masses, is often quoted as the conduction band of $\mathrm{CeO}_{2}$. From our band alignment study (Fig. 4), we found that the $4 \mathrm{f}$ band has a nearly optimal CBO with the CZTS conduction band, while the $5 \mathrm{~d}$ band lies at a much higher energy. Then, we can attribute the complete lack of photocurrent in architecture A1 to the very poor transport properties of the $4 \mathrm{f}$ band. $\mathrm{A} 30 \mathrm{~nm} \mathrm{CeO}_{2}$ layer is therefore thick enough to completely impede electron transport. Instead, when $\mathrm{CeO}_{2}$ is very thin as in architecture A2 (1-5 nm), short circuit current and fill factor losses are greatly diminished and in some cases eliminated (Fig. 5 and S5, supplementary material). This is possibly due to tunneling-based transport between the CZTS and CdS conduction bands through the thin interlayer. Residual current losses, as in Fig. 5, are probably due to thickness inhomogeneity of $\mathrm{CeO}_{2}$, or to the fact that an even thinner layer is necessary. Growth of $\mathrm{CeO}_{2}$ by atomic layer deposition may be beneficial in this respect.

We conclude that inserting a thin lattice-matched $\mathrm{CeO}_{2}$ layer between CZTS and CdS alleviates interface recombination and results in a reproducible open circuit voltage boost in the solar cell. This is attributed to the formation of a high-quality $\mathrm{CZTS} / \mathrm{CeO}_{2}$ heterointerface, with instances of epitaxial growth observed in some regions. We suggest that the open circuit voltage could be further improved if epitaxy could be obtained on a larger scale, if $\mathrm{Ce}_{2} \mathrm{O}_{3}$ inclusions could be decreased, and if the surface coverage could be improved. Etching the CZTS surface immediately prior to $\mathrm{CeO}_{2}$ deposition may facilitate the formation of an epitaxial interface. It should be kept in mind that the very large electron effective mass in the $\mathrm{CeO}_{2}$ conduction band puts a severe constraint on the maximum thickness of the $\mathrm{CeO}_{2}$ film, which should only be a couple of nm thick in order to avoid the dramatic current losses.

See supplementary material for additional TEM images, phase analysis of the $\mathrm{CeO}_{2}$ layer, compositional analysis across the interface, estimation of $\mathrm{CeO}_{2}$ coverage, and more detailed statistics on the solar cell parameters for the reference architecture and architecture A2.

The research leading to these results has received funding from the Danish Council for Strategic Research, from VILLUM Fonden (Grant No. 9455), from the People Programme (Marie Curie Actions) of the European Union's Seventh Framework Programme (FP7/2007-2013) under REA Grant Agreement No. 609405 (COFUNDPostdocDTU), and from the Australian Government through the Australian Renewable Energy Agency (ARENA) (1-USO028) and Australian Research Council (ARC) (DP)(DP120103097). The authors acknowledge the Electron Microscope Unit (EMU) at the Mark Wainwright Analytical Centre (UNSW), Kaiwen Sun (UNSW) for technical assistance, and Zoltan Balogh (DTU CEN) for TEM lamella preparation.

\footnotetext{
${ }^{1}$ M. A. Green, Nat. Energy 1, 1 (2016).

${ }^{2}$ S. Tajima, T. Itoh, H. Hazama, K. Ohishi, and R. Asahi, Appl. Phys. Express 8, 082302 (2015).
} 
${ }^{3}$ M. Courel, J. A. Andrade-Arvizu, and O. Vigil-Galán, Appl. Phys. Lett. 105, 233501 (2014).

${ }^{4}$ K. Sun, C. Yan, F. Liu, J. Huang, F. Zhou, J. A. Stride, M. Green, and X. Hao, Adv. Energy Mater. 6, 1600046 (2016).

${ }^{5}$ C. Platzer-Björkman, C. Frisk, J. K. Larsen, T. Ericson, S.-Y. Li, J. J. S. Scragg, J. Keller, F. Larsson, and T. Törndahl, Appl. Phys. Lett. 107, 243904 (2015).

${ }^{6}$ H. Hiroi, N. Sakai, T. Kato, and H. Sugimoto, in 2013 IEEE 39th Photovoltaic Specialists Conference (PVSC) (IEEE, 2013), pp. 0863-0866.

${ }^{7}$ U. Rau and H. Schock, Appl. Phys. A 69, 131 (1999).

${ }^{8}$ S. Sze and K. K. Ng, Physics of Semiconductor Devices (Wiley, 2004), p. 68.

${ }^{9}$ D. J. Friedman, J. M. Olson, and S. Kurtz, in Handbook of Photovoltaic Science and Engineering, 2nd ed., edited by A. Luque and S. Hegedus (John Wiley \& Sons, Ltd., Chichester, UK, 2011), Chap. 8, p. 338.

${ }^{10}$ U.S. Geological Survey, Fact Sheet 087-02, 2005.

${ }^{11}$ M. Yashima, S. Kobayashi, and T. Yasui, Solid State Ionics 177, 211 (2006).

${ }^{12}$ V. V. Afanas'ev, S. Shamuilia, A. Stesmans, A. Dimoulas, Y. Panayiotatos, A. Sotiropoulos, M. Houssa, and D. P. Brunco, Appl. Phys. Lett. 88, 132111 (2006).

${ }^{13}$ R. Gillen, S. J. Clark, and J. Robertson, Phys. Rev. B 87, 125116 (2013).
${ }^{14}$ C. Yan, F. Liu, K. Sun, N. Song, J. A. Stride, F. Zhou, X. Hao, and M. Green, Sol. Energy Mater. Sol. Cells 144, 700 (2016).

${ }^{15}$ C. Yan, K. Sun, F. Liu, J. Huang, F. Zhou, and X. Hao, Sol. Energy Mater. Sol. Cells 160, 7 (2017).

${ }^{16}$ A. Redinger, D. M. Berg, P. J. Dale, and S. Siebentritt, J. Am. Chem. Soc. 133, 3320 (2011).

${ }^{17}$ H. Unuma, T. Kanehama, K. Yamamoto, K. Watanabe, T. Ogata, and M. Sugawara, J. Mater. Sci. 38, 255 (2003).

${ }^{18}$ R. N. Blumenthal and R. L. Hofmaier, J. Electrochem. Soc. 121, 126 (1974).

${ }^{19}$ D. Mullins, S. Overbury, and D. Huntley, Surf. Sci. 409, 307 (1998).

${ }^{20}$ E. Paparazzo, G. M. Ingo, and N. Zacchetti, J. Vac. Sci. Technol. A 9, 1416 (1991).

${ }^{21}$ G. Graham, W. Weber, C. Peters, and R. Usmen, J. Catal. 130, 310 (1991).

${ }^{22}$ Y. Zhu, N. Jain, M. K. Hudait, D. Maurya, R. Varghese, and S. Priya, J. Vac. Sci. Technol. B 32, 011217 (2014).

${ }^{23}$ F. Liu, C. Yan, J. Huang, K. Sun, F. Zhou, J. A. Stride, M. A. Green, and X. Hao, Adv. Energy Mater. 6, 1600706 (2016).

${ }^{24}$ M. Gloeckler and J. Sites, Thin Solid Films 480-481, 241 (2005).

${ }^{25}$ C. Yan, F. Liu, N. Song, B. K. Ng, J. A. Stride, A. Tadich, and X. Hao, Appl. Phys. Lett. 104, 173901 (2014).

${ }^{26}$ H. F. Wardenga and A. Klein, Appl. Surf. Sci. 377, 1 (2016). 